\title{
RESEARCH
}

Open Access

\section{Symptomatic malignant spinal cord compression in children: a single-center experience}

\author{
Lucia De Martino ${ }^{1 *}$ D, Piero Spennato ${ }^{2}$, Simona Vetrella ${ }^{1}$, Maria Capasso ${ }^{1}$, Carolina Porfito ${ }^{1}$, Serena Ruotolo ${ }^{1}$, \\ Massimo Eraldo Abate' ${ }^{1}$ Giuseppe Cinalli² and Lucia Quaglietta ${ }^{1}$
}

\begin{abstract}
Background: Malignant spinal cord compression (MSCC) is associated withpoor prognosis and may lead to permanent paralysis, sensory loss, and sphincter dysfunction. Very limited data are available on incidence and etiology of MSCC in pediatric population. We aimed to examine etiology, clinical presentation and treatment of pediatric patient with MSCC admitted to the Santobono-Pausilipon Children's Hospital, Naples, Italy.
\end{abstract}

Methods: Forty-four children under 18 yearsadmitedsince 2007 and assessed for MSCC clinical presentations, evaluation, and treatment.were retrospectively collected from our institutional pediatric oncology and neurosurgery database.

Results: The median age at time of MSCC diagnosis was 52 months, with a peak in young ( $\leq 3$ years) patients. The leading cause of MSCC was extramedullary tumors (63.6\%), in particular neuroblastoma (27.2\%) followed by Ewing sarcomas (15.9\%). Cord compression was the presenting feature of a new malignancy in 33 (75\%) patients, and a consequence of metastatic disease progression or relapse in the remaining 11 (25\%) patients. Motor deficit was the initial symptoms of spinal compression in all patients, while pain was present in about $60 \%$ of patients, followed by sphincteric deficit (43.2\%). The primary tumor site was located in the neck in 3 (6.8\%) patients, thorax in 16 (36.4\%), cervico-thoracic region in 3 (6.8\%), thoraco-lumbar region in 8 (18.2\%), abdomen in 5 (11.4\%), lumbar-sacral region in 7 (15.9\%) and thoracic-lumbar-sacral region in 1 (2.3\%). The median length of the interval between symptom onset and tumor diagnosis varied widely from 0 to 360 days in the entire population, however this interval was significantly shorter in patients with known neoplasia in comparisonto patients with new diagnosis (at relapse 7 days [interquartile range 3-10] vs at diagnosis 23 days [7-60]). Pre and post-operative spine magnetic resonance imagingwas performed in all cases, and most(95\%) patients underwent neurosurgical treatment as first treatment. Severe motor deficit was associated with younger age and severe motor deficit at diagnosis was associated withworst motor outcomes at discharge from neurosurgery. Patients with progression or relapsed disease showed a worst prognosis, while the majority of patients (70.5\%) were alive at 5 years after diagnosis.

Conclusions: The natural history of MSCC in children is associated to permanent paralysis, sensory loss, and sphincter dysfunction, thus prompt diagnosis and correct management are needed to minimize morbidity. Treatment strategies differed widely among cancer types and study groups in the absence of optimal evidence-based treatment guidelines. When the diagnosis is uncertain, surgery provides an opportunity to biopsy the lesion in addition to treating the mass.

Keywords: Spinal cord compression, Extramedullary, Intradural, Intramedullary, Motor deficit, Sphincter dysfunction, Pain

\footnotetext{
* Correspondence: demartinoluci@gmail.com

'Department of Pediatric Oncology, Santobono-Pausilipon Children's

Hospital, Posillipo Street, 226, 80122 Naples, Italy

Full list of author information is available at the end of the article
}

(c) The Author(s). 2019 Open Access This article is distributed under the terms of the Creative Commons Attribution 4.0 International License (http://creativecommons.org/licenses/by/4.0/), which permits unrestricted use, distribution, and reproduction in any medium, provided you give appropriate credit to the original author(s) and the source, provide a link to the Creative Commons license, and indicate if changes were made. The Creative Commons Public Domain Dedication waiver (http://creativecommons.org/publicdomain/zero/1.0/) applies to the data made available in this article, unless otherwise stated. 
Table 1 Etiology of Symptomatic Spinal Cord Compression in pediatric patients

\begin{tabular}{|c|c|c|}
\hline Condition & NM-SCC & M-SCC \\
\hline No of cases & 13 & 44 \\
\hline Males, n (\%) & $6(46.1)$ & $20(45.4)$ \\
\hline $\begin{array}{l}\text { Age at diagnosis of SCC, } \\
\text { months, median (IQR; range) }\end{array}$ & $\begin{array}{l}95(23-125 ; \\
4-179)\end{array}$ & $52(20.5-112 ; 0-205)$ \\
\hline \multirow[t]{25}{*}{ Etiology, n (\%) } & Extradural11 (84.5) & Extradural 28 (63.6) \\
\hline & Lipoma 6 (46.1) & $\begin{array}{l}\text { Neuroblastoma } \\
12(27.2)\end{array}$ \\
\hline & $\begin{array}{l}\text { Aneurysmal bone } \\
\text { cyst } 4 \text { (30.7) }\end{array}$ & $\begin{array}{l}\text { Ewing Sarcoma } \\
7(15.9)\end{array}$ \\
\hline & $\begin{array}{l}\text { Osteoblastoma } \\
1(7.7)\end{array}$ & $\begin{array}{l}\text { Yolk SacTumor } \\
2(4.5)\end{array}$ \\
\hline & $\begin{array}{l}\text { Intradural } \\
\text { extramedullary } \\
2(15.4)\end{array}$ & $\begin{array}{l}\text { Metastatic tumors } \\
7(15.9)\end{array}$ \\
\hline & $\begin{array}{l}\text { Meningioma } \\
1(7.7)\end{array}$ & $\begin{array}{l}\text { - Ewing Sarcoma } \\
\text { (chest wall) }\end{array}$ \\
\hline & \multirow{19}{*}{$\begin{array}{l}\text { Plexiform } \\
\text { Neurofibromas } \\
1(7.7)\end{array}$} & $\begin{array}{l}\text { - Ewing Sarcoma } \\
\text { (pelvis) }\end{array}$ \\
\hline & & $\begin{array}{l}\text { - Ewing Sarcoma } \\
\text { (spine) }\end{array}$ \\
\hline & & - Hepatoblastoma \\
\hline & & $\begin{array}{l}\text { - Osteosarcoma } \\
\text { (distalfemur) }\end{array}$ \\
\hline & & $\begin{array}{l}\text { - Rhabdomyosarcoma } \\
\text { (thigh) }\end{array}$ \\
\hline & & $\begin{array}{l}\text { - Rhabdoid Tumor } \\
\text { (kidney) }\end{array}$ \\
\hline & & $\begin{array}{l}\text { Intradural } \\
\text { extramedullary } \\
7 \text { (15.9) }\end{array}$ \\
\hline & & $\begin{array}{l}\text { Malignant } \\
\text { Schwannoma } \\
1(2.3)\end{array}$ \\
\hline & & AT-RT 1 (2.3) \\
\hline & & $\begin{array}{l}\text { Metastatic tumors } \\
5(11.3)\end{array}$ \\
\hline & & - AT-RT \\
\hline & & - Choroid Plexus Carcinoma \\
\hline & & - Medulloblastoma (2) \\
\hline & & $\begin{array}{l}\text { - Suprasellar Germ } \\
\text { Cell Tumor }\end{array}$ \\
\hline & & Intramedullary 9 (20.4) \\
\hline & & Ependymoma 2 (4.5) \\
\hline & & $\begin{array}{l}\text { Pylocitic Astrocytoma } \\
3(6.8)\end{array}$ \\
\hline & & High-Grade Glioma 1 (2.3) \\
\hline & & $\begin{array}{l}\text { Low-Grade Glioma } \\
3(6.8)\end{array}$ \\
\hline
\end{tabular}

NM non malignant, $M$ malignant, SCC spinal cord compression, AT-RT Atypical TeratoidRhabdoidTumor

\section{Introduction}

Malignant spinal cord compression (MSCC) is one of the most feared complications of pediatric spinal cancers [1]. Cord compression may be the presenting feature of a new malignancy, or a consequence of metastatic disease progression or relapse [2-9]. Spinal cord compression (SCC) can be classified into three groups, based on tumor location: extradural (E-SCC), intradural/extramedullary (I/E-SCC), 
and intramedullary (I-SCC), and can be caused by a number of ethiologic mechanisms including direct spread of tumor, extension of tumor through vertebral foramina into epidural space and bony disease within vertebrae with secondary cord compression. In adults, extradural tumors are most common, as they reside in the vertebrae body or structures outside the dura. Intradural-extramedullary tumors are the second most common and come from the leptomeninges or nerve roots inside the dura, but external from the spinal cord. The least common are intramedullary spinal cord tumors which arise from the spinal cord proper, leading to invasion and destruction of the gray and white matter [1]. Despite their impact on patient morbidity and mortality, very limited data are available on incidence and etiology of MSCC in pediatric population [2-9]. Moreover, diagnosis of MSCC in children can be particularly difficult at an early phase, especially in infants, thus increasing short- and longterm morbidity [10]. Yet, further insights in MSCC are key, as its natural history, if untreated, typically entails paralysis, sensory loss, and sphincter dysfunction, and this applies to children as well as to adults. The objective of this study was to examine etiology, clinical presentation and treatment of pediatric patient with MSCC admitted to the SantobonoPausilipon Children's Hospital, Naples, Italy.

\section{Methods}

This retrospective study was carried out at the Department of Pediatric Neurosurgery and Pediatric Oncology of Santobono-Pausilipon Children's Hospital, Naples, Italy, from January 2007 to January 2019. A neurosurgerical and oncology database of all children (age $<=18$ years) with solid tumors has been maintained since 2007. Children, who had documented MSCC but without related symptoms, were not considered for this study. Once children were identified from the database, their health care records were reviewed. Case definitions for MSCC were based on the etiological classifications within the International Spinal Cord Society (ISCoS) core data set for non-traumatic Spinal Cord Injury dataset [11].

\section{Grading of MSCC}

The degree of motor deficit was evaluated by prospectively applying the Spinal Injury Association Impairment Scale adapted to patients' age [12]. It was graded as follows: grade 1, mild hypostenia with walking disability for legs, or difficulty in raising hands above head for arms; grade 2, moderate hypostenia with inability to walk and make movements against gravity or raise the hands above the head; grade 3 , severe hypostenia with paraplegia, no elicitable tendon reflexes or muscular movements. The other main presenting symptoms (sphincter dysfunctions, pain and respiratory distress) were reported as either being present or absent.

\section{Statistics}

Descriptive statistics were used in terms of absolute frequencies and percentages for categorical variables and the Pearson's chi-square test or Fisher's exact test, if appropriate, was applied to compare proportions. Quantitative data were described in terms of median values with their interquartile range (IQR) and differences between groups were assessed by the Mann-Whitney Test. More advanced statistical analysis was not carried out, because the numbers in each diagnostic and etiological group were so low. All

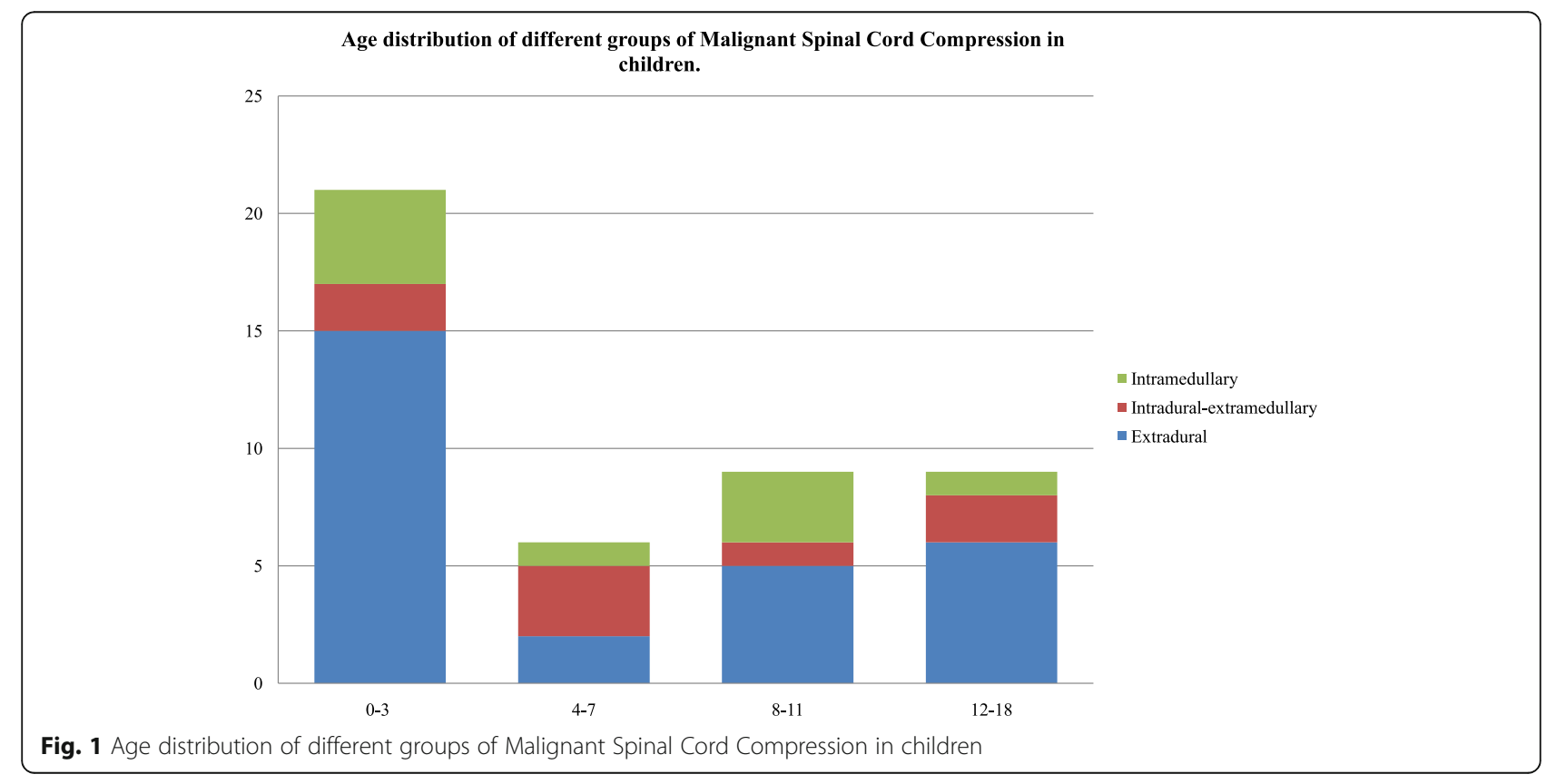


Table 2 Features of Malignant Spinal Cord Compression and Patient Characteristics at Diagnosis

\begin{tabular}{|c|c|c|}
\hline \multirow[t]{2}{*}{ Feature/characteristic } & \multicolumn{2}{|c|}{ At diagnosis } \\
\hline & $N$ & $\%$ \\
\hline No of cases & 44 & 100 \\
\hline \multicolumn{3}{|l|}{ Timing of SCC } \\
\hline At diagnosis & 33 & 75.0 \\
\hline At relapse & 11 & 25.0 \\
\hline \multicolumn{3}{|c|}{ Symptom-diagnosis interval, days } \\
\hline$\leq 7$ & 19 & 43.2 \\
\hline $8-30$ & 11 & 25 \\
\hline$>30$ & 14 & 31.8 \\
\hline \multicolumn{3}{|l|}{ Symptoms } \\
\hline Motor deficit & 44 & 100 \\
\hline Grade 1 & 10 & 22.7 \\
\hline Grade 2 & 19 & 43.2 \\
\hline Grade 3 & 15 & 34.1 \\
\hline Pain & 26 & 59.1 \\
\hline Upper extremities & 3 & 11.5 \\
\hline Lower extremities & 12 & 46.1 \\
\hline Spinal & 11 & 42.3 \\
\hline Irritability & 3 & 6.8 \\
\hline Sphincter dysfunction & 19 & 43.2 \\
\hline Respiratory distress & 2 & 4.5 \\
\hline Spinalcord MRI, N (\%) & 44 & 100 \\
\hline \multicolumn{3}{|c|}{ Level of spinal cord compression } \\
\hline Cervical & 3 & 6.8 \\
\hline Cervico-thoracic & 3 & 6.8 \\
\hline Thoracic & 16 & 36.4 \\
\hline Thoraco-lumbar & 8 & 18.2 \\
\hline Lumbar & 5 & 11.4 \\
\hline Lumbar-sacral & 7 & 15.9 \\
\hline Thoracic-lumbar-sacral & 1 & 2.3 \\
\hline Neurosurgical treatment & 42 & 95.4 \\
\hline
\end{tabular}

tests were two-tailed and a $P$-value $<0.05$ was considered statistically significant. All data were performed by using MedCalc for Windows, version 9.6.4.0 (MedCalc Software, Mariakerke, Belgium).

\section{Results}

\section{Etiology}

Since 2007, a total of 57 patients aged 0-18 years have sustained a tumor SCC. Table 1 displays etiology of the compression. Of these 57 patients, 13 (22.8\%) were excluded from analysis because affected by nonmalignant tumours (NM), leaving 44 evaluable (20 male, $45.4 \%)$ including $28(63.6 \%)$ cases of extradural, 7
(15.9\%) cases of intradural/extramedullary and 9 (20.4) cases of intramedullary tumors. The median age at time of MSCC diagnosis was 52 months (interquartile [IQR] 20.5-112, range 0-205). Age distribution of patients showed a peak in young patients ( $\leq 3$ years old) (Fig. 1 ).

\section{Clinical presentation}

MSCC characteristics at diagnosis are provided in Table 2. Cord compression was the presenting feature of a new malignancy in $33(75 \%)$ patients, a consequence of metastatic disease progression or relapse in the remaining 11 (25\%) patients. The median length of the interval symptom-tumor diagnosis was 11 days (IQR 760; range $0-360$ ) in the entire population and was between 0 and 7 days in 19 patients, 8-30 days in 11, and more than 30 days in 14 . However in patients with known neoplasia the interval was significantly shorter (at relapse 7 days, IQR $2.8-10.3$ vs at diagnosis 22.5 days, IQR 7-60 days, p 0.03752). Motor deficit occurred in all

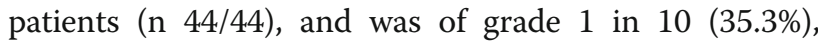
grade 2 in 19 (43.2\%), and grade 3 in 15 (34.1\%). It involved the upper extremities in 5 patients, the lower extremities in 38 , both extremities in 2 . The occurrence of severe motor deficit was more frequent in infants (age $\leq$ 2 years) compared to children older than 2 years (n 10/ $15,22.7 \%$ vsn $5 / 29,11.4 \%$, p 0.0027$)$. The frequency of the other symptoms was $59.1 \%$ (n 26/44) for pain, $43.2 \%$ (n 19/44) for sphincter dysfunction and 6.8\% (n 3/44) for irritability. Pain involved upper extremities in 3 (11.5\%) patients, lower extremities in 12 patients (46.1\%) and back in 11 (42.3) patients. Acute respiratory distress resulting from diaphragmatic paralysis and requiring intubation and mechanical ventilation was observed in 2 patients (4.5\%). Cord compression was documented by magnetic resonance imaging (MRI) in all patients (n 44/44). The primary tumor site was located in the neck in $3(6.8 \%)$ patients, thorax in 16 (36.4\%), cervico-thoracic region in $3(6.8 \%)$, thoraco-lumbar region in $8(18.2 \%)$, abdomen in $5(11.4 \%)$, lumbarsacral region in 7 (15.9\%) and thoracic-lumbar-sacral region in 1 (2.3\%). All patients (n 44/44) underwent spine MRI at SCC diagnosis. First line treatment was neurosurgery in $42(95.4 \%)$ patients and chemotherapy in 2 patients ( 1 neuroblastoma and 1 Malignant Germ Cell Tumor) not operated for high intraoperative risk.

\section{Neurosurgical treatment}

Main features of neurosurgical treatment of patients affected by MSCC are showed in Table 3. A total of 33 (75\%) patients have sustained an E-I/E-SCC and 9 (20.4\%) patients an I-SCC. The median age at time of EI/E-SCC diagnosis was 63 months (IQR 21-129, range 0-205) and at time of I-SCC diagnosis was 48 months 
Table 3 Characteristic of Neurosurgical Treatment of Patients affected by Malignant Extradural-Intradural/Extramedullary and IntramedullarySpinal Cord Compression

\begin{tabular}{|c|c|c|c|}
\hline Feature/characteristic & $E-I / E$ & 1 & $p$ \\
\hline No of cases, N (\%) & $33(75)$ & $9(20.4)$ & \\
\hline Age at diagnosis of SCC,months, median (IQR; range) & $63(21-129 ; 0-205)$ & $48(25-106 ; 10-198)$ & ns \\
\hline Pre-operative spinalcord MRI, N (\%) & $33(100)$ & $9(100)$ & ns \\
\hline NS recovery, days, median (IQR; range) & $6(3-9.3 ; 2-41)$ & $18(14-20 ; 10-32)$ & 0.00112 \\
\hline ICU recovery, hours, median (IQR; range) & $17(0-24 ; 0-984)$ & $24(0-24 ; 0-50)$ & ns \\
\hline Interval NS admission-surgery, days, median (IQR; range) & $0.5(0-1 ; 0-29)$ & $7(3-9 ; 0-18)$ & 0.00228 \\
\hline Post-operative spinal cord MRI, N (\%)* & $33(100)$ & $9(100)$ & ns \\
\hline NS perioperative deaths, N (\%) & $0(0)$ & 0 & ns \\
\hline NS perioperative complications, N (\%) & $4(12.1)$ & 0 & ns \\
\hline -Increased motor deficit & $1(3.0)$ & & \\
\hline -Spinal stenosis & $1(3.0)$ & & \\
\hline -Bilateral lower-limb oedema & $1(3.0)$ & & \\
\hline -Seizures & $1(3.0)$ & & \\
\hline NS resection, N (\%) & & & ns \\
\hline -biopsy & $4(12.1)$ & $0(0)$ & \\
\hline -partial & $26(78.8)$ & $7(77.8)$ & \\
\hline -complete & $3(9.1)$ & $2(22.2)$ & \\
\hline
\end{tabular}

NS NeuroSurgical, ICU Intensive Care Unit, E Extradural, I/E Intradural Extramedullary, I Intramedullary ${ }^{*} \mathrm{MRI}$ within $24 \mathrm{~h}$

\section{Neurosurgical Treatment in Pediatric Patients affected by Extradural-} Intradural/Extramedullary Spinal Cord Compression.

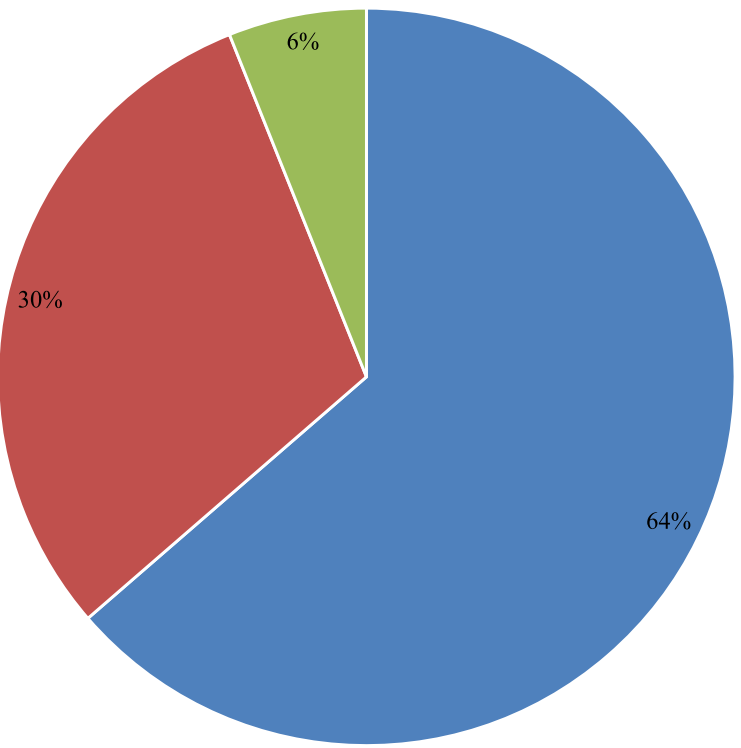

- Laminotomy
- Laminectomy
- Corpectomy

Fig. 2 Neurosurgical Treatment in Pediatric Patients affected by Extradural-Intradural/Extramedullary Spinal Cord Compression 
Table 4 Clinical Response to Neurosurgical Treatment at discharge from Neurosurgery in Patient affected by Malignant Extradural-Intradural/ExtramedullarySpinal Cord Compression

\begin{tabular}{|c|c|c|c|c|c|c|}
\hline & \multicolumn{2}{|c|}{ No change } & \multicolumn{2}{|c|}{ Improvement } & \multicolumn{2}{|c|}{ Normal } \\
\hline & $\bar{N}$ & $\%$ & $\bar{N}$ & $\%$ & $N$ & $\%$ \\
\hline \multicolumn{7}{|l|}{ Grade of Motor Deficit } \\
\hline Grade $1(n=7)$ & 0 & 0 & 4 & 57.1 & 3 & 42.8 \\
\hline Grade $2(n=14)$ & 3 & 21.4 & 10 & 71.4 & 1 & 7.1 \\
\hline Grade $3(n=12)$ & 7 & 58.3 & 4 & 33.3 & 1 & 8.3 \\
\hline
\end{tabular}

(IQR 25-106, range10-198) (p ns). The length of stay in neurosurgery (6 days, IQR 3-9.3, range 2-41 for E-I/ESCC patients and 18 days, IQR14-20, range 10-32 for ISCC; p 0.00112) and the interval from admission in neurosurgery and operation (E-I/E-SCCSCC 0.5 days, IQR $0-1$, range $0-29$ versus I-SCC 7 days, IQR 3-9, range $0-$ 18 ; p 0.00228 ) was significantly different in the two groups. The length of stay in Intensive Care Unit (ICU) was $17 \mathrm{~h}, \mathrm{IQR} 0-24$, range $0-984$ for patients affected E-I/ E-SCC and $24 \mathrm{~h}, \mathrm{IQR}$ 0-24, range 0-50 (p ns). The majority of patients received partial removal (E-I/E-SCC $26 / 33$ vs I-SCC $7 / 9$, p ns). There were no perioperative deaths in the two groups. Post-operative MRI scanning established adequate decompression in all patients, while reoperation was required in 1 patient for spinal stenosis within $36 \mathrm{~h}$. Twenty-one (64\%) patients affected with E-I/ E-SCC underwent laminotomy, 10 (30\%) laminectomy and 2 (6\%) corpectomy (Fig. 2).

\section{Motor deficit at neurosurgery discharge in E-I/E-SCC}

Following neurosurgical treatment for E-I/E-SCC, 5 patients $(11.9 \%)$ achieved complete motor recovery, $18 \mathrm{im}-$ proved (42.8\%), and 10 remained stable (23.8\%) (Table 4). Complete recovery occurred in 3 of 7 patients (42.8\%) with grade 1,1 of $14(7.1 \%)$ of those with grade 2 and 1 of 12 (8.3\%) of those with grade 3 motor deficit. Seven patients (58.3\%) with grade 3 and 3 patients with grade 2 motor deficit showed no improvement after surgery (Table 4).

\section{Five-year survival}

Thirteen patients (29.5\%) died, of which 5 (38.4\%) as a direct result of the tumour, 8 (61.6\%) for metastatic progression or relapse. Details on individual patients are reported in Table 5

\section{Discussion}

Spinal cord compression secondary to cancer is a rare diagnosis but represents an oncology emergency as it may lead quickly to permanent paralysis, if not treated effectively and promptly. Acute compression of the spinal cord occurs in 3 to $5 \%$ of children with cancer, often at diagnosis $[13,14]$. To assess etiology, clinical presentation and treatment of MSCC we evaluated retrospectively 44 children under 18 years with symptomatic MSCC. The median age of our patients was 52 months while Tantawy et al. reported that 8 years was the mean age of their patients [7]. During the study period the leading cause of MSCC in children under 18 years was extramedullary tumors (63.6\%), in particular neuroblastoma (27.2\%) followed by Ewing sarcomas (15.9\%), similarly to previous studies [7-9]. Cord compression was the presenting symptoms of a new cancer in $75 \%$ of cases. Motor deficit was the initial symptoms of spinal compression in all patients, while pain was present in about $60 \%$ of patients, followed by sphincteric deficit (43.2\%). Almost the same observation was reported by De Bernardi et al., who reported that motor deficit was the most presenting MSCC symptom (98.7\%) followed by pain $(61.8 \%)$ and then sphincteric dysfunction (39.5\%) $[6,15]$. The median length of the interval symptomtumor diagnosis varied widely from 0 to 360 days in the entire population, however this interval was significantly shorter in patients with known neoplasia respect to patients with new diagnosis (at relapse 7 days, IQR $2.8-10.3$ vs at diagnosis 22.5 days, IQR 760 days). It is widely accepted that MSCC is considered as a medical emergency and any diagnostic delay should be avoided. For children presenting in District General Hospitals with a strong suspicion of SCC, transfer to a principal treatment centre is recommended because management is highly complex and requires the input of a Neurosurgery and Clinical Oncology. In our case series, pre and post-operative spine MRI was performed in all the cases. It is widely recognized that pre and post contrast MRI spine is the gold standard for diagnosis, and should be performed before $24 \mathrm{~h}$ have elapsed [16]. In our study, severe motor deficit was associated with younger age and severe motor deficit at diagnosis was associated to worst motor outcomes at discharge from neurosurgery. Our patients with progression or relapsed disease showed a worst prognosis, while the majority of patients $(70.5 \%)$ were alive at 5 years after diagnosis. Recently, a systematic review showed that patients with SCC due to NBL differ from patients without intraspinal extension with younger age at diagnosis. Moreover the severity of the neurological motor deficit at diagnosis had the most predictive power for the neurological outcome [17].

Classification in E, I/E and I-SCC is helpful in developing a differential diagnosis and guiding appropriate clinical management. Surgical resection is the treatment of choice for I-spinal tumors leading to SCC. Instead, the discussion whether to perform immediate surgical decompression in cases of E-I/E spinal cord compromise due to cancer is still open. In our case series, the 
Table 5 Details and Long-Term Follow-up of Pediatric Patients affected Malignant Spinal Cord Compression

\begin{tabular}{|c|c|c|c|c|c|c|c|c|c|c|}
\hline ID & Sex & $\begin{array}{l}\text { Level of } \\
\text { SCC }\end{array}$ & Type & $\begin{array}{l}\text { Age at SCC } \\
\text { (months) }\end{array}$ & $\begin{array}{l}\text { Interval symptoms -SCC } \\
\text { diagnosis (days) }\end{array}$ & $\begin{array}{l}\text { Motor deficit } \\
\text { (grade) }\end{array}$ & Diagnosis & $\mathrm{NCH}$ & Status & $\begin{array}{l}\text { Follow-up } \\
\text { (months) }\end{array}$ \\
\hline 1 & $\mathrm{~F}$ & L1-L3 & $E$ & 101 & 7 & 2 & Metastasis of Rhabdomyosarcoma & Yes & Dead & - \\
\hline 2 & $\mathrm{~F}$ & D5-D6 & E & 108 & 4 & 1 & Ewing Sarcoma & Yes & Alive & 61 \\
\hline 3 & M & D9-D11 & E & 195 & 2 & 2 & Metastasis of Ewing Sarcoma & Yes & Alive & 4 \\
\hline 4 & M & C2-D4 & । & 25 & 30 & 2 & PylociticAstrocytoma & Yes & Alive & 92 \\
\hline 5 & M & L1-L3 & E & 46 & 4 & 2 & Neuroblastoma & Yes & Alive & 8 \\
\hline 6 & M & D12-L4 & E & 3 & 2 & 3 & Neuroblastoma & Yes & Alive & 98 \\
\hline 7 & $\mathrm{~F}$ & D4-D11 & I/E & 63 & 120 & 1 & Metastasis of Medulloblastoma & Yes & Alive & 86 \\
\hline 8 & $\mathrm{~F}$ & D9-L1 & $1 / E$ & 36 & 7 & 2 & Metastasis of AT-RT & Yes & Dead & - \\
\hline 9 & M & C4-D5 & E & 13 & 7 & 2 & Neuroblastoma & Yes & Dead & 104 \\
\hline 10 & $\mathrm{~F}$ & D6-D10 & । & 102 & 14 & 3 & Anaplastic Ependymoma & Yes & Alive & 90 \\
\hline 11 & $\mathrm{~F}$ & L5-S1 & I/E & 165 & 60 & 1 & Malignant Schwannoma & Yes & Alive & 13 \\
\hline 12 & $\mathrm{~F}$ & L1-S1 & E & 24 & 12 & 3 & Neuroblastoma & Yes & Alive & 77 \\
\hline 13 & M & D10-D12 & E & 163 & 60 & 3 & Metastasis of Ewing Sarcoma & Yes & Alive & 65 \\
\hline 14 & $\mathrm{~F}$ & D10-D11 & E & 87 & 60 & 3 & Ewing Sarcoma & Yes & Dead & - \\
\hline 15 & $\mathrm{~F}$ & D11-L1 & E & 10 & 7 & 1 & Neuroblastoma & Yes & Alive & 106 \\
\hline 16 & $\mathrm{~F}$ & D7-D9 & E & 39 & 10 & 1 & Neuroblastoma & Yes & LF & - \\
\hline 17 & M & L5-S2 & E & 204 & 30 & 1 & Ewing Sarcoma & Yes & Alive & 24 \\
\hline 18 & $\mathrm{~F}$ & D1-D5 & E & 21 & 7 & 3 & Ewing Sarcoma & Yes & Dead & - \\
\hline 19 & $\mathrm{~F}$ & L4-S1 & E & 171 & 7 & 2 & Metastasis of Osteosarcoma & Yes & LF & - \\
\hline 20 & M & $\mathrm{C} 2-\mathrm{C} 6$ & । & 106 & 360 & 3 & Low Grade Glioma & Yes & Alive & 126 \\
\hline 21 & M & D11-S5 & E & 20 & 60 & 3 & Malignant Germ Cell Tumor & Yes & Alive & 82 \\
\hline 22 & $\mathrm{~F}$ & D1-D3 & । & 42 & 30 & 2 & Low Grade Glioma & Yes & Alive & 28 \\
\hline 23 & $\mathrm{~F}$ & D5-D11 & । & 10 & 90 & 3 & PylociticAstrocytoma & Yes & Alive & 104 \\
\hline 24 & $\mathrm{~F}$ & D10 & I/E & 129 & 20 & 3 & $\begin{array}{l}\text { Metastasis of Malignant Suprasellar } \\
\text { Germ Cell Tumor }\end{array}$ & Yes & Dead & - \\
\hline 25 & M & C2-D2 & । & 48 & 60 & 2 & PylociticAstrocytoma & Yes & Alive & 114 \\
\hline 26 & $\mathrm{~F}$ & D4-D10 & E & 41 & 60 & 1 & Neuroblastoma & Yes & LF & - \\
\hline 27 & $\mathrm{~F}$ & $\mathrm{D} 12-\mathrm{L} 2$ & E & 134 & 7 & 2 & Ewing Sarcoma & Yes & Alive & 60 \\
\hline 28 & M & D8 & I/E & 36 & 2 & 2 & Metastasis of Medulloblastoma & Yes & Dead & - \\
\hline 29 & M & L2-S1 & I/E & 52 & 10 & 1 & AT-RT & Yes & Dead & - \\
\hline 30 & M & D2-D3 & E & 116 & 360 & 1 & Ewing Sarcoma & Yes & Alive & 2 \\
\hline 31 & $\mathrm{~F}$ & L2-L4 & । & 107 & 240 & 1 & Ependymoma & Yes & Alive & 39 \\
\hline 32 & M & L2-L4 & E & 2 & 0 & 3 & Metastasis of renal RT & Yes & Dead & - \\
\hline 33 & M & D11-L3 & E & 0 & 0 & 3 & Neuroblastoma & Yes & Alive & 23 \\
\hline 34 & $\mathrm{~F}$ & D8-L5 & I/E & 79 & 7 & 2 & $\begin{array}{l}\text { Metastasis of Choroid Plexus } \\
\text { Carcinoma }\end{array}$ & Yes & Dead & - \\
\hline 35 & M & D11-L3 & E & 8 & 2 & 3 & Neuroblastoma & Yes & Alive & 46 \\
\hline 36 & $\mathrm{~F}$ & L2-S2 & E & 19 & 60 & 3 & Neuroblastoma & None & Alive & 60 \\
\hline 37 & M & L3-S1 & I/E & 147 & 15 & 2 & Neuroblastoma & Yes & Dead & - \\
\hline 38 & M & D2-D4 & E & 205 & 7 & 2 & Metastasis of Ewing Sarcoma & Yes & Dead & - \\
\hline 39 & M & C5 & E & 90 & 3 & 2 & Metastasis of Hepatoblastoma & Yes & Dead & - \\
\hline 40 & $\mathrm{~F}$ & $\mathrm{~L} 5$ & । & 198 & 30 & 2 & High Grade Glioma & Yes & Alive & 2 \\
\hline 41 & $\mathrm{~F}$ & D10-L2 & । & 18 & 180 & 2 & Ganglioglioma & Yes & Alive & 94 \\
\hline 42 & $\mathrm{~F}$ & D7-D9, L3 & E & 14 & 60 & 2 & Malignant Germ Cell Tumor (Yolk Sac) & None & Alive & 104 \\
\hline 43 & M & D2-D6 & E & 11 & 9 & 3 & Neuroblastoma & Yes & Alive & 91 \\
\hline 44 & $\mathrm{~F}$ & C6 & E & 101 & 7 & 2 & Ewing Sarcoma & Yes & Alive & 42 \\
\hline
\end{tabular}

LF Lost to Follow-up, AT-RT Atypical Teratoid-Rhaboid Tumor, RT Rhaboid Tumor 
majority of patients ( 95\%) underwent neurosurgical treatment as first treatment with adequate decompression, independently of the etiology and there were no perioperative deaths. Children with $\mathrm{E}$ and $\mathrm{I} / \mathrm{E}$ underwent neurosurgical treatment in less than $24 \mathrm{~h}$, while patients with I-tumors in about 7 days. Due to the complexity of the surgery in case of I-SCC, patients stayed longer in ICU and neurosurgical department. In case of E-I/ESCC the primary role of neurosurgery has been replaced for chemotherapy since Hayes et al. start pioneering the use of primary chemotherapy in management of NBL with intraspinal extension [18]. Results of various retrospective studies showed that chemotherapy can be an effective initial treatment option in NBL and Ewing Sarcoma,however population size of these studies is too small to make definite conclusions. [15, 17, 19]. Actually, a SIOPEN prospective study registry of Peripheral NeuroblasticTumours (PNTs) presenting with spinal canal involvement aims to describe the natural history of PNTs presenting with SCC and describe the diagnostic and therapeutic approaches adopted in participating centers. As results from this and other clinical studies will become available, physicians will be able to make better-informed decisions on treatment for future pediatric patients.

Limitations of this work are several, and of course include the retrospective, observational, single-center design. In addition, we did not focus on the inclusion of asymptomatic MSCC, and thus additional studies are required to confirm our findings in general, and in particular to detail the outlook of MSCC without symptoms or clinical signs.

\section{Conclusions}

The natural history of MSCC typically entails a poor prognosis as well as permanent paralysis, sensory loss, and sphincter dysfunction. This case series emphasize the need to consider cancer in the differential diagnosis of more common diseases in pediatric patients, especially because early diagnosis and proactive treatment are vital to improve prognosis and survival. For children with a high suspicion of MSCC, transfer to a principal centre is recommended because management is complex and requires multidisciplinary discussion about best treatment. Moreover, a child with history of cancer who develops back/extremity pain should be considered to have spinal cord compromise until proved otherwise. Spine MRI is the gold standard for diagnosis, and should be performed before $24 \mathrm{~h}$ have elapsed. Treatment strategies differ widely among cancer types and study groups in the absence of optimal evidence-based treatment guidelines. When the diagnosis is uncertain, surgery provides an opportunity to biopsy the lesion in addition to treating the mass.

\section{Acknowledgements}

We are grateful to all the participants that contributed to this study and to the staff of Neurosurgery and Neuro-oncology of the Santobono-Pausilipon Children's Hospital for their cooperation and support in the collection of samples. We thank the parents who agreed to participate in the study.

\section{Authors' contributions}

LQ and GC provided medical assistance to the patient and collected medical information; LDM revised the literature; PS supervised the clinical examination included in the case report; MEA supervised the examination included in the case report; MC and SR was involved in the clinical follow-up of the patient; SV supervised the patient treatment plan. All authors read and approved the final manuscript.

\section{Funding}

No funding has been provided for the research.

\section{Availability of data and materials}

The dataset and analyses are available from the corresponding author on reasonable request.

\section{Ethics approval and consent to participate}

This study was approved by the Santobono-Pausilipon Children's Hospital Ethics Committee. The guardian (parents) of the patient consented to both participation and publication of the case.

\section{Consent for publication}

Informed consent was obtained from the guardian (parents), who agreed to join this study, and using the medical information for scientific research and publication.

\section{Competing interests}

The authors declare that they have no competing interests.

\section{Author details}

${ }^{1}$ Department of Pediatric Oncology, Santobono-Pausilipon Children's Hospital, Posillipo Street, 226, 80122 Naples, Italy. ${ }^{2}$ Department of Pediatric Neurosurgery, Santobono-Pausilipon Children's Hospital, Naples, Italy.

Received: 8 April 2019 Accepted: 20 June 2019

\section{References}

1. Ruppert LM. Malignant spinal cord compression: adapting conventional rehabilitation approaches. Phys Med Rehabil Clin N Am. 2017;28(1):101-14.

2. Costacurta ML, et al. Epidemiological profile of a pediatric population with acquired spinal cord injury from AACD: São Paulo/Brazil. Spinal Cord. 2010; 48(2):118-21.

3. Galvin J, Scheinberg A, New PW. A retrospective case series of pediatric spinal cord injury and disease in Victoria, Australia. Spine (Phila Pa 1976). 2013;38(14):E878-82

4. Sharpe AN, Forsyth R. Acute paediatric paraplegia: a case series review. Eur J Paediatr Neurol. 2013;17(6):620-4.

5. Smith E, Finn S, Fitzpatrick P. Epidemiology of pediatric traumatic and acquired nontraumatic spinal cord injury in Ireland. Top Spinal Cord Inj Rehabil. 2017;23(3):279-84.

6. De Bernardi B, et al. Neuroblastoma with symptomatic spinal cord compression at diagnosis: treatment and results with 76 cases. J Clin Oncol. 2001;19(1):183-90

7. Tantawy AA, et al. Spinal cord compression in childhood pediatric malignancies: multicenter egyptian study. J Pediatr Hematol Oncol. 2013; 35(3):232-6

8. Pollono $D$, et al. Spinal cord compression: a review of 70 pediatric patients. Pediatr Hematol Oncol. 2003;20(6):457-66.

9. Gunes $D$, et al. Paravertebral malignant tumors of childhood: analysis of 28 pediatric patients. Childs Nerv Syst. 2009;25(1):63-9.

10. Simon T, et al. Short- and long-term outcome of patients with symptoms of spinal cord compression by neuroblastoma. Dev Med Child Neurol. 2012; 54(4):347-52.

11. New PW, Marshall R. International spinal cord injury data sets for nontraumatic spinal cord injury. Spinal Cord. 2014;52(2):123-32. 
12. Rosman NP. G.H., Spinal Cord Injury. In: Swaiman KF, Ashwal S, editors Pediatric Neurology: Principles and Practice, vol. 954. 3rd ed. St Louis: MO: Mosby; 1999. p. 966.

13. Lewis DW, et al. Incidence, presentation, and outcome of spinal cord disease in children with systemic cancer. Pediatrics. 1986;78(3):438-43.

14. Klein SL, Sanford RA, Muhlbauer MS. Pediatric spinal epidural metastases. J Neurosurg. 1991;74(1):70-5.

15. De Bernardi B, et al. Neuroblastoma with symptomatic epidural compression in the infant: the AIEOP experience. Pediatr Blood Cancer. 2014;61(8):1369-75.

16. Sun $H$, Nemecek AN. Optimal management of malignant epidural spinal cord compression. Hematol Oncol Clin North Am. 2010;24(3):537-51.

17. Kraal K, et al. Treatment and outcome of neuroblastoma with intraspinal extension: a systematic review. Pediatr Blood Cancer. 2017;64(8):e26451.

18. Hayes FA, et al. Chemotherapy as an alternative to laminectomy and radiation in the management of epidural tumor. J Pediatr. 1984;104(2):221-4.

19. Mirzaei $L$, et al. The neurological compromised spine due to Ewing sarcoma. What first: surgery or chemotherapy? Therapy, survival, and neurological outcome of 15 cases with primary Ewing sarcoma of the vertebral column. Neurosurgery. 2015;77(5):718-24; discussion 724-5.

\section{Publisher's Note}

Springer Nature remains neutral with regard to jurisdictional claims in published maps and institutional affiliations.

Ready to submit your research? Choose BMC and benefit from:

- fast, convenient online submission

- thorough peer review by experienced researchers in your field

- rapid publication on acceptance

- support for research data, including large and complex data types

- gold Open Access which fosters wider collaboration and increased citations

- maximum visibility for your research: over $100 \mathrm{M}$ website views per year

At BMC, research is always in progress.

Learn more biomedcentral.com/submissions 